\title{
IMPROVING SOME INEQUALITIES ASSOCIATED WITH THE EULER-MASCHERONI CONSTANT
}

\author{
JENICA CRINGANU
}

Abstract. The aim of this paper is to improve the results obtained by Chen and Mortici in 2013 about the inequalities for the Euler-Mascheroni constant.

Mathematics subject classification (2010): 40A05, 33B15, 11 Y60.

Keywords and phrases: Sequence, convergence, Euler-Mascheroni constant.

\section{REFERENCES}

[1] H. AlZER, Inequalities for the gamma and polygamma functions, Abh. Math. Sem. Univ. Hamburg 68 (1998) 363-372.

[2] G. D. Anderson, R. W. Barnard, K. C. Richards, M. K. Vamanamurthy, M. Vuorinen, Inequalities for zero-balanced hypergeometric functions, Trans. Amer. Math. Soc. 345 (1995) 1713 1723.

[3] C. P. CHEN, Inequalities for the Euler-Mascheroni constant, Applied Mathematics Letters 23 (2010) $161-164$.

[4] C. P. Chen, C. Mortici, Limits and inequalities associated with the Euler-Mascheroni constant, Applied Mathematics and Computation 219 (2013) 9755-9761.

[5] D. W. DeTemple, A quicker convergence to Euler's constant, Amer. Math. Monthly 100 (5) (1993) $468-470$.

[6] C. Mortici, A. Vernescu, An improvement of the convergence speed of the sequence $\left(\gamma_{n}\right)_{n \geqslant 1}$ converging to Euler's constant, An. Stiint. Univ. "Ovidius" Constanta 13 (1) (2005) 97-100.

[7] C. Mortici, A. Vernescu, Some new facts in discrete asymptotic analysis, Math. Balkanica (NS) 21 (Fasc. 3-4) (2007) 301-308.

[8] T. NEGOI, A faster convergence to the constant of Euler, Gazeta Matematica Seria A 15 (1997) $111-$ 113 (in Romanian).

[9] S. R. Tims, J. A. TyRreL, Approximate evaluation of Euler's constant, Math. Gaz., 55 (1971) 65-67.

[10] L. Tотн, Problem E3432, Amer. Math. Monthly, 98 (3) (1991) 264.

[11] L. Toth And J. Bukor, On the alternating series $1-\frac{1}{2}+\frac{1}{3}-\frac{1}{4}+\ldots$, J. Math. Anal. Appl. 282 (2003) 21-25.

[12] R. M. YounG, Euler's constant, Math. Gaz. 75 (472) (1991) 187-190. 